\title{
Investigation of the Antibacterial Activity of Syzygium aromaticum Essential Oils
}

\author{
Binnur Mericli Yapici (Corresponding author) \\ Canakkale Onsekiz Mart University, Faculty of Arts and Sciences, \\ Biology of Department, Canakkale, Turkey \\ E-mail: byapici@comu.edu.tr \\ Merve Calisgan \\ Canakkale Onsekiz Mart University, \\ Graduate School of Natural and Applied Sciences, Canakkale, Turkey \\ E-mail: mervecalisgan@hotmail.com
}

This work was financially supported by the Canakkale Onsekiz Mart University Scientific Research Projects Coordination Unit. (Project number: FYL-2017-1140)

\begin{abstract}
In this study, the antibacterial activity of Syzygium aromaticum commercial essential oils against eight different clinical bacteria was investigated. Five different commercial essential oils, the research material, were obtained from the market. Proteus mirabilis, Shigella dysenteriae, Serratia marcescens, Pseudomonas aeruginosa, Staphylococcus haemolyticus, Staphylococcus caprae, Staphylococcus epidermidis and Staphylococcus aureus were used as clinical bacteria in the study. Antibacterial activity of commercial essential oils was determined by disk diffusion and Minimum Inhibition Concentration (MIC) tests. Disc diffusion findings obtained from essential oils against clinical bacteria were evaluated by comparing them with findings from various antibiotics. By considering the results of disk diffusion, the MIC values of three commercial oils were determined. When the results of the research were evaluated in general, two different commercial essential oils of Syzygium aromaticum species were found to be more effective than antibiotics against tested bacteria. In the next stages of the research, it is planned to determine the chemical components of commercial essential oils by GC-MS analysis and to demonstrate the effectiveness of essential oils on bacterial cells by electron microscopy.
\end{abstract}

Keywords: Clov bud, Essential oil, Clinic bacteria, Antimicrobial activity.

DOI: $10.7176 / J S T R / 6-10-02$

\section{Syzygium aromaticum Uçucu Yağlarının Antibakteriyal Aktivitesinin İncelenmesi}

Özet

$\mathrm{Bu}$ araştırmada sekiz farklı klinik bakteriye karşı Syzygium aromaticum ticari uçucu yağlarının antibakteriyal aktivitesi araştırılmıştır. Araştırma materyali olan beş farklı ticari uçucu yağ piyasadan temin edilmiştir. Çalışmada klinik bakteri olarak Proteus mirabilis, Shigella dysenteriae, Serratia marcescens, Pseudomonas aeruginosa, Staphylococcus haemolyticus, Staphylococcus caprae, Staphylococcus epidermidis ve Staphylococcus aureus kullanılmıştır. Ticari uçucu yağların antibakteriyal aktivitesi disk difüzyon ve Minimum İnhibisyon Konsantrasyonu (MIK) testleri ile belirlenmiştir. Klinik bakterilere karşı uçucu yağlardan elde edilen disk difüzyon bulguları çeşitli antibiyotiklerden elde edilen bulgular ile karşılaştırılmak suretiyle değerlendirilmiştir. Disk difüzyon sonuçları dikkate alınarak etkili bulunan üç ticari yağın MíK değerlerleri tespit edilmiştir. Araştırma

11 | P a g e

www.iiste.org 
sonuçları genel olarak değerlendirildiğinde; Syzygium aromaticum türüne ait iki farklı ticari uçucu yağın klinik bakterilere karşı antibiyotiklerden daha etkili olduğu tespit edilmiştir. Araştırmanın bundan sonraki aşamalarında ticari ucu yağların GC-MS analizi ile kimyasal bileşenlerinin belirlenmesi ve elektron mikroskobu ile uçucu yağların bakteriyal hücreler üzerine etkinliklerinin gösterilmesi planlanmaktadır.

Anahtar kelimeler: Karanfil tomurcuğu, Uçucu yağ, Klinik bakteriler, Antimikrobiyal aktivite

\section{Giris}

Bitkisel ilaçlar, gelişen toplulukların kültür ve geleneklerinin önemli bir parçasını oluşturmaktadır (Niyogi SK., 2005). Yüzyıllardır antimikrobiyal aktiviteye sahip olduğu bilinen ve özellikle hastalıkların tedavisinde kullanılan uçucu yağların günümüzde birçok tıbbi özellikleri açığa çıkarılmaktadır. Günümüzde çeşitli bitkilerden elde edilen bitkisel ekstraktlar; çiğ ve işlenmiş gıdaların muhafaza edilmesinde, alternatif tıp ve doğal terapiler de dahil olmak üzere ilaç olarak da kullanılmaktadır (Hammer ve ark., 1999). Uçucu yağların diğer etken maddelere göre az toksisite göstermeleri durumunda hastalıkların tedavisi için tercih edilebilecekleri araştırıcılar tarafindan ifade edilmektedir (Belmekki ve ark., 2013). Doğada yetişen 300'e yakın bitki ailesinden yaklaşık 1/3'ü uçucu yağ asidi içermekte ve antimikrobiyal bileşenler çoğunlukla uçucu yağ kısmında yer almaktadır. Karanfil tomurcuğu yemeğe tat vermesi, karanfil çayı (rahatlatıcı etki) olarak tüketilmesi, ağız kokusunu gidermesi gibi sebeplerle halk tarafindan çokça kullanılmaktadır. Karanfil (Syzgium aromaticium) ağacından toplanan karanfil tomurcukları iyice kurutulduktan sonra ögütülüp baharat haline de getirilmektedir. Omega 3 ve omega 6 yağ asitlerinin en çok bulunduğu ender bitkilerden olan karanfil yüksek oranda uçucu yağ içermektedir. A, K, E ve B6 vitaminleri açısından oldukça zengin olan karanfil, aynı zamanda kalsiyum, magnezyum, sodyum ve potasyum deposudur. İçerisinde bulundurduğu bileşikler sindirimi sağlayan enzimler içerdiğinden sindirimi kolaylaştırmaktadır. Ayrıca ağrı kesici etkisi bulunması sebebi ile diş ve diş eti hastalıklarında da kullanılmaktadır. Karanfil tomurcuğu aynı zamanda tıpta cilt ve deri hastalıklarında ve saç sağlığı için kullanılmaktadır. Vücudumuzda önemli problemlere neden olan patojen bakterileri öldürme özelliği nedeniyle karanfil tomurcuğu ilaç endüstrisi için ön planda olabilecek bir ürün olarak görülmektedir. Uçucu yağlar ile patojen bakterilerle mücadelede ve birçok ilaca dirençli patojen bakterilerin kontrolünü sağlamada karanfilin kullanılmasının gerekli olduğu araştırmacılar tarafindan ifade edilmektedir (Akthar ve ark., 2014).

Yukarıda belirtilen literatür bilgileri ışı̆̆ında çalışmamızda sekiz farklı klinik bakteriye karşı beş farklı ticari Szygium aromaticum uçucu yağının antibakteriyal aktivitesi araştırılmıştır. Araştırma sonuçlarının; bundan sonra yapılacak olan çalışmalara katkı sağlaması beklenmektedir.

\section{Materyal ve Yöntem}

Araştırma materyali olan ve piyasadan temin edilen beş farklı ticari Szygium aromaticum uçucu yağının (TK1, TK2, TK3, TK4, TK5) antibakteriyal aktivitesi Proteus mirabilis, Shigella dysenteriae, Serratia marcescens, Pseudomonas aeruginosa, Staphylococcus haemolyticus, Staphylococcus caprae, Staphylococcus epidermidis ve Staphylococcus aureus klinik bakterilerine karşı araş̧ırılmıştır. Klinik bakteriler Çanakkale Onsekiz Mart Üniversitesi, Fen Edebiyat Fakültesi, Biyoloji Bölümü, Temel ve Endüstriyel Mikrobiyoloji laboratuvarından elde edilmiştir.

Araştırmada kullanılan ticari uçucu yağların klinik bakterilere karşı antibakteriyel aktiviteye sahip olup olmadığ disk difüzyon yöntemi ile belirlenmiştir. Stok kültürler $37^{\circ} \mathrm{C}$ 'de 24 saatlik bir aktivasyondan sonra Mc-Farland cihazı ile konsantrasyonları $10^{6} \mathrm{kob} / \mathrm{ml}$ 'ye ayarlanmış ve bu kültürler Disk Difüzyon Yönteminde kullanılmıştır. Boş diskler negatif ve çeşitli antibiyotik diskler ise pozitif kontrol olarak değerlendirilmiştir.

Triptic Soy Agar (TSA) içeren petriler $37^{\circ} \mathrm{C}^{\prime}$ de 24 saat boyunca inkübe edildikten sonra oluşan inhibisyon zon çapları $\mathrm{mm}$ cinsinden ölçülmüsşür. $\mathrm{Bu}$ çalışmalar tripletli olarak yürütülmüsşür (EUCAST, 2015). Disk difüzyon sonuçları dikkate alınarak etkili bulunan üç farklı ticari yağın Minimum İnhibisyon Konsantrasyonu (MIK) değerleri tespit edilmiştir. MíK değerlerinin belirlenmesinde mikroplak tekniği kullanılmıştır. Ticari uçucu yağların $\% 8$ ile $\% 0,015625$ arasında değişen MiK konsantrasyonları Mueller-Hinton Broth (MHB, Merck) besiyerinde yapılmıştır. Bu yöntemde kullanılan kültürlerin yoğunluğu yine Mc-Farland cihazı ile $10^{6} \mathrm{kob} / \mathrm{ml}$ olarak ayarlanmıştır. Plakalar $37^{\circ} \mathrm{C}^{\prime}$ de 24 saat inkübe edildikten sonra her bir kuyucuğa $20 \mu 1 \% 1$ 'lik steril tetrazolium klorür

12 | P a g e

www.iiste.org 
ilave edilerek $20 \mathrm{dk}$. bekletildikten sonra üremelerin olup olmadığı hem renk değişimi ve hem de TSA içeren petrilere $5 \mu \mathrm{l}$ hacimde damla ekim yöntemi ile değerlendirilmiştir. TSA içeren petriler $37^{\circ} \mathrm{C}$ ' de 24 saat inkübe edildikten sonra üremenin olup olmadığı kontrol edilerek Minimum İnhibitör Konsantrasyon değerleri belirlenmiştir (EUCAST, 2015).

\section{Bulgular ve Tartışma}

Araştırmada kullanılan TK1, TK2, TK3, TK4, TK5 uçucu yağlarının öncelikle Proteus mirabilis, Shigella dysenteriae, Serratia marcescens, Pseudomonas aeruginosa klinik bakterilerine karşı elde edilen inhibisyon zon çapı değerleri sırasıyla Çizelge 1'de verilmiş ve bulgularımız diğer araştırıların bulguları ile karşılaştırılmıştır.

Çizelge 1: Proteus mirabilis, Shigella dysenteriae, Serratia marcescens, Pseudomonas aeruginosa klinik bakterilerine karşı ticari karanfil uçucu yağlarının inhibisyon zon çapları.

\begin{tabular}{|l|l|l|l|l|}
\hline & \multicolumn{4}{|c|}{ İnhibisyon Zon Çap1 Değerleri (mm) } \\
\hline & \multicolumn{4}{|c|}{ Klinik Bakteriler } \\
\hline $\begin{array}{l}\text { Uçucu Yağ ve } \\
\text { Antibiyotikler }\end{array}$ & $\begin{array}{l}\text { Proteus } \\
\text { mirabilis }\end{array}$ & $\begin{array}{l}\text { Shigella } \\
\text { dysenteriae }\end{array}$ & $\begin{array}{l}\text { Serratia } \\
\text { marcescens }\end{array}$ & $\begin{array}{l}\text { Pseudomonas } \\
\text { aeroginosa }\end{array}$ \\
\hline TK1 & 14,25 & 17,83 & 10,00 & 15,00 \\
\hline TK2 & 42,50 & 69,00 & 45,50 & 59,00 \\
\hline TK3 & 14,25 & 12,50 & 20,75 & 20,50 \\
\hline TK4 & 06,00 & 10,00 & 12,50 & 06,00 \\
\hline TK5 & 06,00 & 06,00 & 06,00 & 06,00 \\
\hline Amoxycillin & 06,00 & 06,00 & 06,00 & 06,00 \\
\hline Cefixime & 10,00 & 06,00 & $-*$ & 32,00 \\
\hline Vancomycin & 06,00 & 06,00 & - & - \\
\hline Tetracycline & 06,00 & 06,00 & 09,25 & 06,00 \\
\hline Fosfomycin/trometamol & 14,00 & - & - & 06,00 \\
\hline Ampicillin & - & 06,00 & 06,00 & 06,00 \\
\hline Kanamycin & - & - & 16,16 & - \\
\hline Gentamicin & - & - & 14,50 & - \\
\hline
\end{tabular}

*-: Testedilmedi

Araştırma bulgularına göre Proteus mirabalis klinik bakterisine karşı TK2 ticari uçucu yağından 42,50 mm, TK1 ve TK3 ticari uçucu yağlarının her ikisinden de 14,25 mm'lik inhibisyon zon çapı değerleri elde edilmiştir. Proteus mirabalis bakterisine karşı pozitif kontrol olarak denenen beş farklı antibiyotikten sadece Cefixime ve Fosfomycin/trometamol antibiyotiklerinden srrasiyla $10,00 \mathrm{~mm}$ ve 14,00 mm inhibisyon zon çap1 değerleri tespit edilmiştir. Ancak bu değerler özellikle TK2 uçucu yağından elde edilen değere göre oldukça düşük bulunmuştur. Çalışmada incelenen TK4 ve TK5 ticari uçucu yağlarının ise klinik bakteriye karşı etkili olmadığ 1 belirlenmiştir. Dorman ve Deans (2000), tarafından karanfil uçucu yağının Proteus vulgaris NCIB 4175 bakteri izolatına karşı 44,60 mm'lik inhibisyon zon çapı değeri tespit edildiği bildirilmiştir. Saeed ve Tariq (2008), Syzgium aromaticum uçucu yağının Proteus mirabilis bakteri izolatına karşı antimikrobiyal aktivitesini 16,50 mm olarak belirlemişlerdir. Prabuseenivasan ve ark (2006), tarafından Proteus vulgaris bakteri izolatına karşı 4 farklı konsantrasyonda Syzgium aromaticum uçucu yağının disk difüzyon bulguları sırasıyla 20,10 mm, $18,20 \mathrm{~mm}, 11,80 \mathrm{~mm}, 08,00 \mathrm{~mm}$ olarak tespit edilmiştir. Çalışmamızda TK2 ticari uçucu yağından Proteus mirabilis bakterisine karşı elde dilen İnhibisyon zon çap1 değeri; hem araştırmamızda kullanılan antibiyotiklerden hem de diğer araştırıcıların bulgulardan daha yüksek bulunmuştur.

13 | P a g e

www.iiste.org 
Çalışmamızda Shigella dysenteriae bakterisine karşı TK2 uçucu yağından 69,00 mm, TK1, TK3 ve TK4 ticari uçucu yağlarından ise sırasıyla $17,83 \mathrm{~mm}, 12,50 \mathrm{~mm}$ ve10,00 mm inhibisyon zon çap1 değerleri tespit edilmiştir. Ancak TK5 uçucu yağı ve denenen beş farklı antibiyotik Shigella dysenteriae bakterisine karşı herhangi bir etkinlik sergilememiştir. Hersch-Martínez ve ark. (2005), Syzgium aromaticum uçucu yağının Shigella sonnei bakteri izolatına karşı 21,70 mm inhibisyon zon çap1 verdiğini bildirmişlerdir. Arora ve Kaur (2007), agar difüzyon metodu ile Syzygium aromaticum sulu ekstraktının Shigella flexneri MTCC 1457 suşuna karşı inhibisyon zon çapı değerini 13,00 mm olarak tespit etmişlerdir. Saeed ve Tariq (2008), Syzygium aromaticum uçucu yağının ve sulu ekstraktının Shigella dysenteria suşuna karşı antimikrobiyal aktivitesini araştırmışlar ve uçucu yağın inhibisyon zon çapı değerini 16,50 mm olarak belirlemişler ancak sulu ekstraktın ise etkili olmadığını ifade etmişlerdir. Shigella dysenteria dizanteri hastalığına neden olan önemli bir insan patojenidir. TK2 ticari uçucu yağından Shigella dysenteria klinik izolatına karşı 69,00 mm'lik oldukça yüksek inhibisyon zonu elde edilmiştir. Bu değer diğer araştırcıların bulgularına göre bu klinik bakteri için de yine daha yüksek bulunmuştur.

Araştırmamızda çalışılan diğer bir klinik bakteri Serratia marcescens için TK2 uçucu yağından 45,00 mm gibi yüksek bir inhibisyon zon değeri elde edilmiş, TK1, TK3 ve TK4 ticari uçucu yağlarından ise sırasıly 10,00 mm, 20,75 mm, 12,50 mm'lik TK2'ye göre daha küçük inhibisyon zon çap1 değerleri belirlenmiştir. Serratia marcescens klinik bakterisine karşı Kanamycin, Gentamicin ve Tetracycline antibiyotiklerinden sırasıyla $\quad 16,16 \mathrm{~mm}, 14,50 \mathrm{~mm}$ ve $9,25 \mathrm{~mm}$ inhibisyon zon çapı değerleri elde edilirken Amoxylin ve Ampicillin antibiyotiklerinin bu bakteriye etkili olmadığ Hersch-Martínez ve ark. (2005), Syzgium aromaticum uçucu yağının Serratia marcescens bakterisine karşı inhibisyon zon çapı değerini 9,00 mm olarak bildirmişlerdir. Dorman ve Deans (2000), ise Syzgium aromaticum uçucu yağının Seratia marcescens NCIB 1377 bakterisine karşı inhibisyon zon değerini 18,90 mm olarak tespit etmişlerdir. Araştırma sonuçlarımıza göre Serratia marcescens izolatına karş1 TK2 ve TK3 ticari uçucu yağlarının çalışılan diğer yağlardan ve farklı araştırıcıların bulgularından daha yüksek sonuçlar verdiği tespit edilmiştir. TK1 ve TK4 ticari uçucu yağları antimikrobiyal aktivite sergilemişler ancak kullanılan bazı antibiyotiklerden daha küçük inhibisyon zonu vermişlerdir.

Çalışmamızda Pseudomonas aeruginosa bakterisine karşı TK2 uçucu yağından 59,00 mm gibi dikkate değer bir inhibisyon zon çapı değeri tespit edilmiştir. Diğer yandan TK1 ve TK3' uçucu yağlarından sırasıyla $15,00 \mathrm{~mm}$ ve $20,50 \mathrm{~mm}$ gibi daha düşük inhibisyon zon çapı değerleri elde edilmiştir. TK4 ve TK5 ticari uçucu yağları ise bu bakteri üzerinde herhangi bir etkinlik sergilememişlerdir. Pseudomonas aeruginosa bakterisine karşı çalışılan antibiyotiklerden sadece Cefixime antibiyotiğinden 32,00 mm inhibisyon zon çapı değeri elde edilirken geri kalan antibiyotiklerin tamamının bu bakteriye karşı etkili olmadığ1 tespit edilmiştir. Goni ve ark (2009) tarafindan Syzgium aromaticum uçucu yağının Pseudomonas aeruoginosa bakteri izolatına karşı 12,00 mm'lik inhibisyon zon çapı değeri tespit edilmiştir. Arora ve Kaur (2007), Syzgium aromaticum sulu ekstraktının Pseudomonas aeruginosa suşuna karşı 10,00 mm inhibisyon zonu verdiğini bildirmişlerdir. Araştırmamızda kullanılan TK2 ticari uçucu yağından Pseudomonas aeruginosa izolatına karşı elde edilen İnhibisyon zon çap1 değeri Cefixime antibiyotiğinden elde edilen değerden ve diğer araştırıcıların bulgularından daha yüksek bulunmuştur.

Araştırmamızda ayrıca TK1, TK2, TK3, TK4, TK5 uçucu yağlarının Staphylococcus genusuna ait dört farklı klinik bakteriye karşı antibakteriyal aktivitesi araştırılmıştır. Stafilokok türlerine karşı ticari karanfil uçucu yağlarının etkinliğini değerlendirmek amacıyla pozitif kontrol olarak Linezolid, Clindamycine, Oxacillin, Bacitracin, Amoxyllin, Vancomycin ve Methicillin antibiyotikleri kullanılmıştır. Staphylococcus haemolyticus, Staphylococcus caprae, Staphylococcus epidermidis and Staphylococcus aureus klinik bakterilerine karşı elde edilen inhibisyon zon çapı değerleri ise Çizelge 2'te verilmiştir. 
Çizelge 2: Staphylococcus genusuna ait dört farklı klinik bakteriye karşı ticari karanfil uçucu yağlarının inhibisyon zon çapı değerleri

\begin{tabular}{|c|c|c|c|c|}
\hline & \multicolumn{4}{|c|}{ 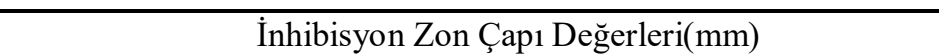 } \\
\hline & \multicolumn{4}{|c|}{ Klinik Bakteriler } \\
\hline $\begin{array}{l}\text { Uçucu Yağ ve } \\
\text { Antibiyotikler }\end{array}$ & S.haemolyticus & S. caprae & S.epidermidis & S. aureus \\
\hline TK1 & 31,50 & 17,16 & 60,00 & 16,25 \\
\hline TK2 & 48,50 & 52,00 & 29,50 & 31,25 \\
\hline TK3 & 11,75 & 15,83 & 13,50 & 14,25 \\
\hline TK4 & 06,00 & 14,80 & 06,00 & 06,00 \\
\hline TK5 & 06,00 & 06,00 & 06,00 & 06,00 \\
\hline Linezolid & 25,50 & 06,00 & 06,00 & 12,50 \\
\hline Clindamycin & 06,00 & 06,00 & 06,00 & 10,00 \\
\hline Oxacillin & 06,00 & 06,00 & 06,00 & 10,50 \\
\hline Bacitracin & 06,00 & 06,00 & 06,00 & 06,00 \\
\hline Amoxycillin & 06,00 & 06,00 & 06,00 & 06,00 \\
\hline Vancomycin & 24,50 & 06,00 & 06,00 & 06,00 \\
\hline Methicillin & 06,00 & 06,00 & 06,00 & 06,00 \\
\hline
\end{tabular}

Staphylococcus haemolyticus bakterisine karşı TK1, TK2, TK3 uçucu yağlarından sırasıyla 31,00 mm, 48,50 mm ve 11,75 mm inbisyon zon çap1 değerleri tespit edilirken TK4 ve TK5 uçucu yağları bu bakteriye karşı etkili bulunmamıştır. Linezolid ve Vancomycin antibiyotiklerinden ise bu bakteriye karşı sırasıyla 25,50 mm ve 24,50 mm'lik inhibisyon çapı değerleri elde edilmiştir. Çalışmamızda Staphylococcus caprae bakterisine karşı TK1, TK2, TK3 ve TK4 uçucu yağlarından sırasılyla 17,16 $\mathrm{mm}, 52,00 \mathrm{~mm}, 15,83 \mathrm{~mm}$ ve 14,80 mm'lik inhibisyon zon çap1 değerleri tespit edilmiştir. Ancak denenen antibiyotiklerin hiçbirisi bu bakteriye karşı antibakteriyal aktivite sergilememiştir. Staphylococcus epidermidis klinik bakterisine karşı beş farklı ticari uçucu yağın sadece ikisinden inhibisyon zonu elde edilmiştir. Buna göre TK2 ve TK3 uçucu yağlarından sırasıyla 29,50 mm ve 13,50 mm'lik inhibisyon zon çapı değerleri tespit edilmiştir. Yine denenen antibiyotiklerin hiçbirisi bu bakteriye karş1 da etkili olmamıştır. Son olarak Staphylococcus aureus bakterisine karş1 TK1, TK2 ve TK3 uçucu yağlarından sırasıyla 16,25 mm, 31,25 mm ve 14,25 mm inbisyon zon çapı değerleri belirlenmiştir. TK4 ve TK5 uçucu yağları çalışmada kullanılan diğer birçok klinik bakteride olduğu gibi Staphylococcus aureus bakterisine karşı da antibakteriyal aktivite sergilememişlerdir. Linezolid, Clindamycin ve Oxacillin antibiyotiklerinden ise sirasıyla $12,50 \mathrm{~mm}, 10,00 \mathrm{~mm}$ ve $10,50 \mathrm{~mm}$ inhibisyon çapı değerleri elde edilmiştir. Dorman ve Deans (2000), Syzygium aromaticum uçucu yağının Staphylococcus aureus NCIB 6571 bakterisine karşı inhibisyon zon çapı değerini 17,60 mm, Goni ve ark. (2009) Staphylococcus aureus bakteri izolatına karş1 19,00 mm olarak belirlemişlerdir. Hersch-Martínez ve ark. (2005), Koagülaz negatif Staphylococcus ve Staphylococcus aureus türüne karşı Syzygium aromaticum uçucu yağlarının inhibisyon zon çapı değerlerini sırasıyla 12,90 mm, 14,30 mm olarak bulmuşlardır. Özdikmenli ve Zorba (2014), Syzygium aromaticum uçucu yağının Staphylococcus aureus türüne karşı 25,00 mm ve ayrıca Metisilin dirençli Staphylococcus aureus suşu için 19,00 mm inhibisyon zon çap1 değeri tespit ettiklerini bildirmişlerdir. Önceki çalışmalarda Syzygium aromaticum uçucu yağının antimikrobiyal aktivitesinin değerlendirilmesinde Stafilokok genusuna ait sadece Staphylococcus aureus bakterisi tercih edilmiştir. Araştırmamızda ise Staphylococcus haemolyticus, Staphylococcus caprae, Staphylococcus epidermidis and Staphylococcus aureus olmak üzere Stafilokok genusuna ait dört farklı klinik bakteriye karşı ticari Syzygium 
aromaticum uçucu yağlarının antibakteriyal aktivisi araştırılmıştır. Bu yönüyle araştırma sonuçlarımız literatüre katk1 sağlar niteliktedir. Bununla birlikte Staphylococcus haemolyticus, Staphylococcus caprae, Staphylococcus epidermidis klinik bakterileri için TK2 den elde edilen inhibisyon zon çap1 değerlerinin dikkate değer olduğu söylenebilir. Çalışmamızda kullanılan ve metsilin dirençli olan Staphylococcus aureus için yine TK2'den elde edilen 31,25 mm'lik inhibisyon zon çapı değeri diğer araştırıcıların tespit ettikleri değerlere göre daha yüksek bulunmuştur.

Çalş̧ma bulgularımıza göre daha etkili olduğu tespit edilen TK1, TK2 ve TK3 uçucu yağlarının MİK değerleri araştırılmış ancak TK3 uçucu yağının belirlediğimiz MíK değer aralığında sonuç vermediği tespit edilmiştir. Bu nedenle klinik bakterilere karşı sadece TK1 ve TK2 uçucu yağlarından elde edilen MíK değerleri çizelgede verilmiştir (Çizelge 3).

Çizelge 3: Klinik bakterilere karşı TK1 ve TK2 uçucu yağlarının MİK değerleri

\begin{tabular}{|l|l|l|}
\hline & \multicolumn{2}{|c|}{ Uçucu Yağlar } \\
\hline Klinik Bakteriler & TK1 & TK2 \\
\hline Proteus mirabilis & $\% 0,50$ & $\% 0,125$ \\
\hline Shigella dysenteriae & $\% 0,25$ & $\% 0,125$ \\
\hline Pseudomonas aeruginosa & $\% 8$ & $\% 0,125$ \\
\hline Serratia marcescens & $\% 0,25$ & $\% 0,0625$ \\
\hline Staphylococcus haemolyticus & $\% 0,50$ & $\% 0,50$ \\
\hline Staphylococcus caprae & $\% 0,0625$ & $\% 0,0625$ \\
\hline Staphylococcus epidermidis & $\% 0,0625$ & $\% 0,125$ \\
\hline Staphylococcus aureus & $\% 0,50$ & $\% 0,25$ \\
\hline
\end{tabular}

Çalışmada araştırılan klinik bakterilerin birçoğuna karşı TK2 uçucu yağından TK1 uçucu göre yağına göre daha düşük MİK değerleri elde edilmiştir. Bu sonuç ise TK2 ve TK1 uçucu yağlarından elde edilen disk difüzyon bulgularını destekler nitelikte olmuştur.

Araştırmamızda TK1, TK2, TK3, TK4, TK5 gibi 5 farklı ticari Szygium aromaticum uçucu yağının Proteus mirabilis, Shigella dysenteriae, Serratia marcescens, Pseudomonas aeruginosa, Staphylococcus haemolyticus, Staphylococcus caprae, Staphylococcus epidermidis ve Staphylococcus aureus gibi klinik bakterilere karşı antibakteriyal aktivitesi araştırılmıştır. Çalışmamızda kullanılan bu bakteriler insan sağlığını tehdit edebilen klinik bakteriler arasında yer almaktadır. Proteus enfeksiyonlarının yüzde doksanı Proteus mirabilis olarak ortaya çıkmaktadır. Proteus enfeksiyonunun en yaygın klinik bulguları idrar yolu enfeksiyonlarıdır. Sık sık yaşanan böbrek taşı problemi altta yatan kronik bir Proteus infeksiyonunun göstergesi olabilmektedir (Foris ve Snowden 2017). Serratia marcescens çoğunlukla yara enfeksiyonları, üriner sistem enfeksiyonları, pnömoni, menenjit gibi merkezi sinir sistemi enfeksiyonları ve kan dolaşımı enfeksiyonları da dahil olmak üzere çok çeşitli klinik hastalığa neden olmaktadır (Ogtrop ve ark., 1997). Shigella dysenteria genellikle kontamine yiyecek ve su yoluyla vücuda alınmakta, barsaklarda inflamasyon ve kanamaya neden olmaktadır. İlaç direncinin küresel olarak ortaya çıkması nedeniyle, Shigella dysenteria tedavisinde antimikrobiyal ajanların seçimi sınırlı kalmaktadır (Niyogi, 2005). Pseudomonas aeruginosa, hastane infeksiyonlarının önde gelen etkenlerinden biridir ve birçok antibiyotiğe doğal olarak dirençli olan bu bakteri aynı zamanda tedavi sırasında da direnç geliş̧irebilmesi nedeni oldukça tehlikelidir.

Staphylococcus suşlarının en önemli kontaminasyon kaynağını çiğ hayvansal gıdalar, hastane alet ve ekipmanları oluşturmaktadır. Bu bakteri türleri kuru yüzeylerde yaşamakta olup, septisemiye ve toksik şok sendromu ile ölüme neden olabilmektedir. Özellikle metisiline dirençli Staphylococcus aureus (MRSA) infeksiyonları giderek artmakta ve ciddi problemler yaratmaktadır. Yapılan araştırmalar sonucunda hastanelerden izole edilen Staphylococcus aureus bakterilerinin yaklaşı \%80'ninin metsiline dirençli olduğu sonucuna varılmıştır. Varılan başka bir sonuç ise Staphylococcus aureus 
bakterilerinin Vankomisin duyarlılığındaki azalmadır (Sancak B., 2011). Araştırma bulgularımız da bu sonuçları destekler nitelikte bulunmuştur.

Sonuç olarak; çalışmamızda incelenen Szygium aromaticum uçucu yağlarından TK1 ve TK2 uçuçu yağlarının disk difüzyon ve MIK bulgularına göre dikkate değer antibakteriyal aktiviye sahip olduğu belirlenmiştir. Klinik bakterilere karşı denenen antibiyotiklerin birçoğunun, hatta bazı bakterilere karşı tamamının etkisiz olduğu bulunmuştur. Araştırmanın bundan sonraki aşamalarında incelenen beş farklı ticari uçucu yağın GS-MS analizlerinin yapılması ve etkili bulunan TK1 ve TK2 uçucu yağlarının bazı klinik bakterilere karşı etkinliğinin elektron mikroskobu ile değerlendirilmesinin gerekli olduğu kanaatine varılmıştır.

\section{Kaynaklar}

Akthar M. S., Degaga B. ve Azam T., 2014. Antimicrobial Activity of Essential oils Extracted from Medicinal Plants Againts the Pathogenic Microorganisms: A Rewiew. Issues in Biological Sciences and Pharm aceutical Research. 2 (1): 001-007.

Arora D. S., Kaur G. J., 2007. Antibacterial Activity of Some Indian Medicinal Plants. J Nat Med 61: 313-317.

Belmekki N., Bendimerad N., Bekhechi C. ve Fernandez X., 2013. Chemical Analysis and Antimicrobial Activity of Teucrium polium L. Essential Oil from Western Algeria. Academic Journals, 7 (14):897-902.

Bercion R., Demartin M., Recio C., Massamba P-M., Frank T., Escribá J. M., Grimont F., Grimont P. A. D., Weill F-X., 2006. Molecular Epidemiology od Multidrug-Resistant Shigella dysenteriae type 1 Causing Dysentery Outbreaks in Central African Republic, 2003-2004. Transactions of the Royal Society of Tropical Medicine and Hygiene.

Dorman H. J. D., Deans S. G., 2000. Antimicrobial Agents from Plants: Antibacterial Activity of Plant Volatile Oils. Journal of Applied Microbiology 88: 308-316.

EUCAST, 2015. Antimikrobik Duyarlılık Testine Yönelik EUCAST Disk Difüzyon Yöntemi. Sürüm 5.0, Ocak.

EUCAST, 2016. The European Committee on Antimicrobial Susceptibility Testing. Breakpoint Tables for Interpretation of MICs and Zone Diameters. Version 6.0, Ocak.

Fabio A., Cermelli C., Fabio G., Nicoletti P., Quaglio P., 2007. Screening of the Antibacterial Effects of a Variety of Essential Oils on Microorganisms Responsible for Respiratory Infections. Phytotherapy Research 21: 374-377.

Foris, L.A., and Snowden, J. 2017. Proteus Mirabilis Infections. In StatPearls. StatPearls Publishing. Available from http://www.ncbi.nlm.nih.gov/pubmed/28723046 [accessed 19 November 2017].

Goñi P., López P., C. Sánchez C., R. Gómez-Lus R., Becerril R., Nerín C., 2009. Antimicrobial activity in the vapour phase of a combination of cinnamon and clove essential oils. Food Chemistry 116, 982-989.

Hammer K. A., Carson C. F., Riley T. B., 1999. Antimicrobial Activity of Essential Oils and Other Plant Extracts. Journal of Applied Microbiology 86: 985-990.

Hersch-Martínez P., Leaños-Miranda B. E., Solórzano-Santos F., 2005. Antibacterial Effects of Commercial Essential Oils over Locally Prevalent Pathogenic Strains in Mexico. Fitoterapia 76: 453-457.

17 I P a g e

www.iiste.org 
Niyogi SK., 2005.Shigellosis. Journal of Microbiology 43(2):133-143.

Sancak B., 2011. Staphylococcus aureus ve Antibiyotik Direnci. Mikrobiyol Bul. 45(3): 565-576.

Saeed S. Tarıq P., 2008. In VitroAntibacterial Activity of Clove Against Gram Negative Bacteria. Pakistan Journal of Botany, 40 (5): 2157-2160.

Ogtrop ve ark., 1997. Serratia marcescens infections in neonatal departments: description of an outbreak and review of the literatüre. Jornal of the Hospital Infection. 1997 Jun;36(2):95-103.

Özdikmenli S., Zorba N. N, 2014. Uçucu Yağların Staphylococcus aureus Üzerine Etkisi. Türk Tarım - Gida Bilim ve Teknoloji Dergisi, 2(5): 228-235.

Prabuseenivasan S., Jayakumar M., Ignacimuthu S., 2006. In vitro antibacterial activity of some plant essential oils. BMC Complementary and Alternative Medicine 2006, 6:39.

Xinxian L., Xuemei C., Yagang C., Won-Chung W. J., Zebin W., Qitang W., 2011. Isolation and Characterization Endophytic Bacteria from hyperaccumulator Sedum alfredii Hance and their potential to promote phytoextraction of zinc polluted soil. World J Microbiol Biotechnol 27: 1197-1207. 